\title{
Infection of Brachypodium distachyon with Selected Grass Rust Pathogens
}

\author{
Michael Ayliffe, ${ }^{1}$ Davinder Singh, ${ }^{2}$ Robert Park, ${ }^{2}$ Matthew Moscou, ${ }^{3}$ and Tony Pryor ${ }^{1}$ \\ ${ }^{1}$ CSIRO Plant Industry, Box 1600, Clunies Ross Street, Acton, Canberra, 2601, Australia; ${ }^{2}$ The University of Sydney, Plant \\ Breeding Institute Cobbitty, Private Bag 11, Camden, NSW, 2570, Australia; ${ }^{3}$ The Sainsbury Laboratory, Norwich Research \\ Park, Norwich, NR4 7UH, United Kingdom
}

Submitted 15 January 2013. Accepted 8 April 2013.

\begin{abstract}
The model temperate grass Brachypodium distachyon is considered a nonhost for wheat rust diseases caused by Puccinia graminis f. sp. tritici, $P$. triticina, and $P$. striiformis. Up to 140 Brachypodium accessions were infected with these three rust species, in addition to $P$. graminis ff. spp. avena and phalaridis. Related $B$. distachyon lines showed similar cytological nonhost resistance (NHR) phenotypes, and an inverse relationship between $P$. graminis f. sp. tritici and $P$. striiformis growth was observed in many lines, with accessions that allowed the most growth of $P$. graminis $\mathbf{f}$. sp. tritici showing the least $\boldsymbol{P}$. striiformis development and vice versa. Callose deposition patterns during infection by all three rust species showed similarity to the wheat basal defense response while cell death that resulted in autofluorescence did not appear to be a major component of the defense response. Infection of $B$. distachyon with $P$. graminis $f$. sp. avena and $P$. graminis f. sp. phalaridis produced much greater colonization, indicating that $P$. graminis rusts with Poeae hosts show greater ability to infect $B$. distachyon than those with Triticeae hosts. $P$. striiformis infection of progeny from two $B$. distachyon families demonstrated that these NHR phenotypes are highly heritable and appear to be under relatively simple genetic control, making this species a powerful tool for elucidating the molecular basis of NHR to cereal rust pathogens.
\end{abstract}

The mechanisms of plant resistance to adapted microbial species are becoming increasingly understood, with the roles of pathogen-associated molecular patterns (PAMPs) and effector molecules and their recognition by plant PAMP receptors and plant resistance genes, respectively, established in many species (Jones and Dangl 2006). In contrast, the interaction between plants and nonadapted pathogens (i.e., nonhost resistance [NHR]) is more poorly defined, although significant mechanistic overlap appears to exist between host and NHR mechanisms (Fan and Doerner 2012; Schulze-Lefert and Panstruga 2011). Current models suggest that layers of defense exist to prevent nonadapted pathogens from colonizing nonhost plants, which range from passively preformed physical and chemical defenses to active pathogen recognition followed by defense activation (Fan and Doerner 2012; Heath 2000; Jones and

Corresponding author: M. Ayliffe; E-mail: michael.ayliffe@csiro.au

* The $\boldsymbol{e}$-Xtra logo stands for "electronic extra" and indicates that one supplementary figure and one supplementary table are published online.

(C) 2013 The American Phytopathological Society
Dangl 2006). This model is best illustrated in the infection process of powdery mildew, where several plant genes essential for epidermal penetration resistance to nonadapted mildews have been identified (PEN1 to PEN3) (Collins et al. 2003; Lipka et al. 2005; Stein et al. 2006). Underlying this penetration barrier is a second defense layer involving genes such as EDS1, PAD4, and SAG101, which are components of salicylic acid (SA)-mediated defenses (Fan and Doerner 2012). The PEN2 gene has also been implicated in NHR of Arabidopsis to Magnaporthe oryzae (Nakao et al. 2011).

The growth of rust pathogens on nonhost plant species has been examined for several plant-pathogen interactions. In two cases, these have involved a nonhost plant that is not closely related to the hosts of the rust pathogens, i.e., Uromyces vignae (the bean rust pathogen) and Puccinia triticina (the wheat leaf rust pathogen) growth on Arabidopsis (Mellersch and Heath 2003; Shafiei et al. 2007). In both cases, modest pathogen growth was apparent that was dependent upon the genotype of the nonhost plant, and the resistance response involved both SA and reactive-oxygen-mediated defenses. In contrast to this relatively extreme divergence between pathogen host and nonhost, in an analysis of "near NHR", in which the pathogen can grow on a few accessions of a species, the growth of $P$. triticina on barley was examined. Resistance was polygenic, with quantitative trait loci (QTL) showing map locations similar to genes conferring partial resistance to the adapted barley rust pathogen P. hordei (Jafary et al. 2008).

Previously, we have examined the interaction between cereal rust pathogens and rice (Ayliffe et al. 2011). Rice is atypical in that it is an agricultural species that is a nonhost of all known rust species. The resistance of rice to rust is not predominantly due to a basic incompatibility or prehaustorial defense mechanisms, because five different cereal rust pathogen species were shown to infect and enter the rice leaf through stomata and colonize underlying plant mesophyll cells with haustoria (Ayliffe et al. 2011). The NHR response of rice to cereal rust infection was shown to be an active response involving the production of hydrogen peroxide and the deposition of callose. Genetic variation in the NHR response was observed, with some rice cultivars supporting more pathogen growth than others (Ayliffe et al. 2011). However, this variation was relatively subtle and prone to environmental effects, making identification of the underlying genes a difficult proposition.

In contrast to rice, the model grass Brachypodium distachyon is a host to a rust pathogen species, $P$. brachypodii, which infects a number of Brachypodium spp. (Barbieri et al. 2011). Phylogenetic studies based upon ribosomal RNA intergenic spacer sequences indicate that $P$. brachypodii is more closely related to $P$. striiformis than other rust species, including $P$. 
graminis and $P$. triticina (Zambino and Szabo 1993). Resistance to an isolate of $P$. brachypodii was shown to be quantitatively inherited in a cross between $B$. distachyon accessions Bd3-1 and Bd1-1, with three QTL identified that collectively explained 39 to $54 \%$ of the variance in seedlings and $22 \%$ of the variance in older plants (Barbieri et al. 2012).

The NHR interaction of Brachypodium spp. with $P$. hordei, $P$. triticina, and P. striiformis ff. spp. tritici and hordei has previously been reported to involve macroscopic symptoms (Draper et al. 2001). Several Brachypodium accessions showed tissue browning upon $P$. striiformis infection, and sporulating pustules were observed on two hexaploid accessions, ABR100 and ABR105 (Catalan et al. 2012; Draper et al. 2001). These hexaploid accessions have subsequently been classified as a separate species, B. hybridum (Catalan et al. 2012). Upon infection with $P$. triticina, symptoms were less obvious, with only a single accession showing brown flecking, whereas several accessions showed browning to $P$. hordei (Draper et al. 2001). The ability of $P$. striiformis to sporulate on Brachypodium accessions was subsequently confirmed in a later study of 119 Brachypodium accessions challenged with $P$. striiformis ff. spp. tritici, hordei, and bromi (Barbieri et al 2012). In all, $79 \%$ of the plant accession-rust isolate interactions produced no macroscopic symptoms, while $29 \%$ produced small or large dark flecks, and a single accession (PI227011) produced sporulating uredinia upon challenge with either $P$. striiformis f. sp. hordei or $P$. striiformis f. sp. bromi but not $P$. striiformis f. sp. tritici (Barbieri et al. 2012). This accession is also hexaploid (Vogel et al. 2006) and, hence, now also considered as B. hybridum (Catalan et al. 2012).

More recently, infection of eight accessions of $B$. distachyon (Bd1-1, Bd2-3, Bd3-1, Bd18-1, Bd21, Bd21-3, Bd29-1, and Bd30-1) with P. graminis ff. spp. tritici, lolii, and phlei-pratensis was reported (Figueroa et al. 2013). Sporulating lesions were observed on most accession upon infection with $P$. graminis ff. spp. lolli and phlei-pratensis but rarely with $P$. graminis f. sp. tritici. Prehaustorial resistance mechanisms were suggested to play a major role against this latter pathogen species (Figueroa et al. 2013).

The small genome size of $B$. distachyon and increasing genomic resources of this species potentially makes it a model system for the molecular analysis of NHR mechanisms to cereal rust pathogens. A number of collections of Brachypodium accessions are publically available, with many accessions derived from the Mediterranean region. Some collections have used a unique prefix (e.g., ABR, Bd, and BdTr) followed by an accession number to designate each accession (Filiz et al. 2009; Garvin et al. 2008; Vogel et al. 2006, 2009). Other collections have assigned different prefixes within a collection to reflect the geographical location where the plants were collected (e.g., Gaz, Tek, Adi, and so on) (Vogel et al. 2009). The phylogenetic relationship among many of these plants is known from simplesequence repeat marker analyses (Vogel et al. 2009). These accessions were essentially divided into two main groups by Vogel and colleagues (2009), with one group consisting of TEK1-10 (excluding TEK3), BdTr1-1, BdTr7a and BdTr7b, and six BdTr8 accessions (hereafter referred to as the TEK group), and the remainder of the accessions forming a second group (hereafter referred to as group 2). These two groups were further divided into smaller clades, with the number of accessions within a single clade ranging from 1 to 17 (Vogel et al. 2009).

To further understand the NHR interaction of cereal rust pathogens with $B$. distachyon, we have undertaken an extensive cytological analysis of over $140 \mathrm{~B}$. distachyon accessions infected with $P$. graminis ff. spp. tritici, aveneae, and phalaridi; $P$. striiformis $\mathrm{f}$. sp. tritici; and $P$. triticina. These microscopic analyses provide further biological insight into the range of macroscopic lesions and immunity previously reported to occur upon challenge of Brachypodium spp. with wheat rust pathogen species (Barbieri et al. 2012; Draper et al. 2001; Figueroa et al. 2013). In addition, in two B. distachyon families, we show that the NHR phenotypes to $P$. striiformis infection are heritable and appear to be controlled by relatively few genes.

\section{RESULTS}

Infection of Brachypodium spp. with rusts of the Triticeae $P$. graminis f. sp. tritici infection.

In all, 140 different $B$. distachyon accessions were infected with $P$. graminis f. sp. tritici, and the development of rust symptoms was analyzed cytologically 4 weeks postinoculation. Macroscopic symptoms varied from apparent immunity in some lines to the formation of lesions ranging from sparse to common (Fig. 1A). In some instances, small pustules were also produced (discussed below). In all, $25 \%$ of accessions showed no symptoms, $19 \%$ showed relatively obvious lesions, and $7 \%$ of accessions produced small sporulating uredinia. The remaining lines had an intermediate phenotype (Supplementary Table S1).

All accessions were analyzed microscopically and each had leaves infected with urediniospores that had germinated and successfully entered the Brachypodium leaf via the formation of an appressorium over a stomate and subsequent production of substomatal vesicles, infection hyphae, and haustoria, regardless of whether macroscopic symptoms were obviously apparent or not. No accession had the ability to completely prevent growth of this $P$. graminis f. sp. tritici isolate via prehaustorial defense mechanisms. In contrast, Figueroa and colleagues (2013) suggested that prehaustorial resistance mechanisms played a major role in the response of eight $B$. distachyon accessions to $P$. graminis $\mathrm{f}$. sp. tritici. Six of these accessions were included in our study, three of which showed relatively extensive $P$. graminis f. sp. tritici growth, including sporulation in one instance (Bd2-3, Bd3-1, and Bd21-3). These differences may reflect $P$. graminis f. sp. tritici race specificity in the $B$. distachyon response or, alternatively, may be due to differences between infection conditions used in the two studies.

On accessions showing no obvious macroscopic symptoms, such as $\mathrm{Bd} 21$, a range of infection site sizes was observed that varied from little more than a substomatal vesicle to larger infections that encompassed multiple mesophyll cells, with small sites and larger sites in close juxtaposition (Fig. 1C1 to C5). The frequency of these larger infection sites was significantly lower when compared with small infection sites (Fig. 2, $\mathrm{Bd} 21 / P$. graminis f. sp. tritici). Very occasionally, much larger infection sites were observed that encompassed several hundred mesophyll cells and which resulted in macroscopic lesion formation; however, the rarity of these infections sites made them difficult to discriminate visually from unrelated wounding events that occur occasionally on glasshouse grown plants.

Microscopic analysis of $B$. distachyon accessions that showed obvious macroscopic symptoms, such as BdTr13g, also identified a range of infection site sizes from very small to large, with small infection sites generally far more abundant (Fig. 1D1). However, among these smaller infection sites were much larger infections that encompassed hundreds of mesophyll cells and which produced small sporulating pustules in some instances (Fig. 1D1 and D2). Almost invariably, the occurrence of macroscopic lesions on the leaf surface of $B$. distachyon accessions corresponded precisely to the production of underlying large rust infection sites (Fig. 1D3 and D4). The full development of macroscopic symptoms took between 3 and 4 weeks postinfection, which is substantially longer than 
the development of $P$. graminis f. sp. tritici on susceptible wheat. After this period of time, many infected $B$. distachyon leaves had begun to undergo age-dependent senescence, suggesting that more growth of this obligate biotrophic pathogen was unlikely to occur.

Visual symptoms therefore represent only a small fraction of $P$. graminis f. sp. tritici infections on $B$. distachyon and a con- tinuum of infection site sizes was observed on all accessions. Difference in the relative frequency of large infection sites enables macroscopic differentiation between apparently immune accessions and those allowing more rust growth. The presence of macroscopic lesions on $B$. distachyon accessions upon $P$. graminis f. sp. tritici infection is not indicative of an extreme resistance response but, rather, increased fungal growth com-
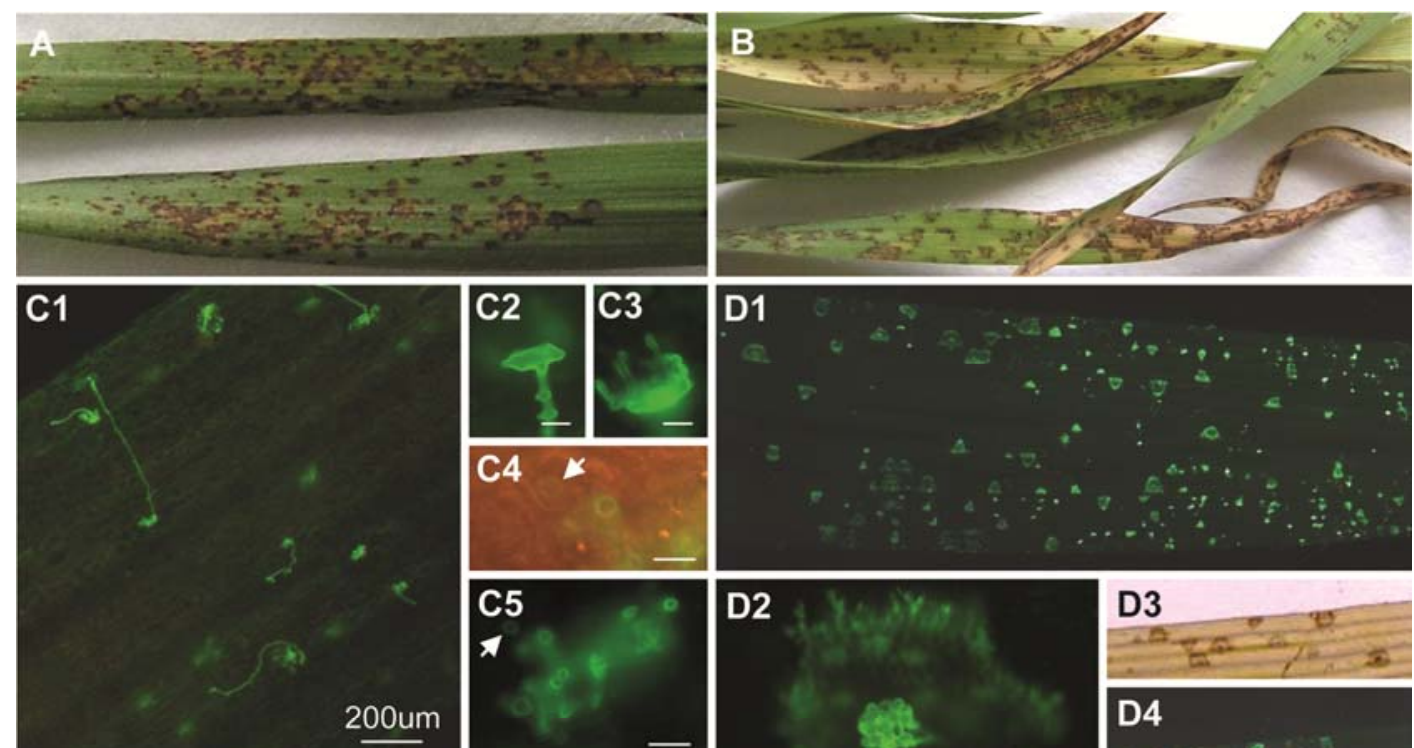

D1
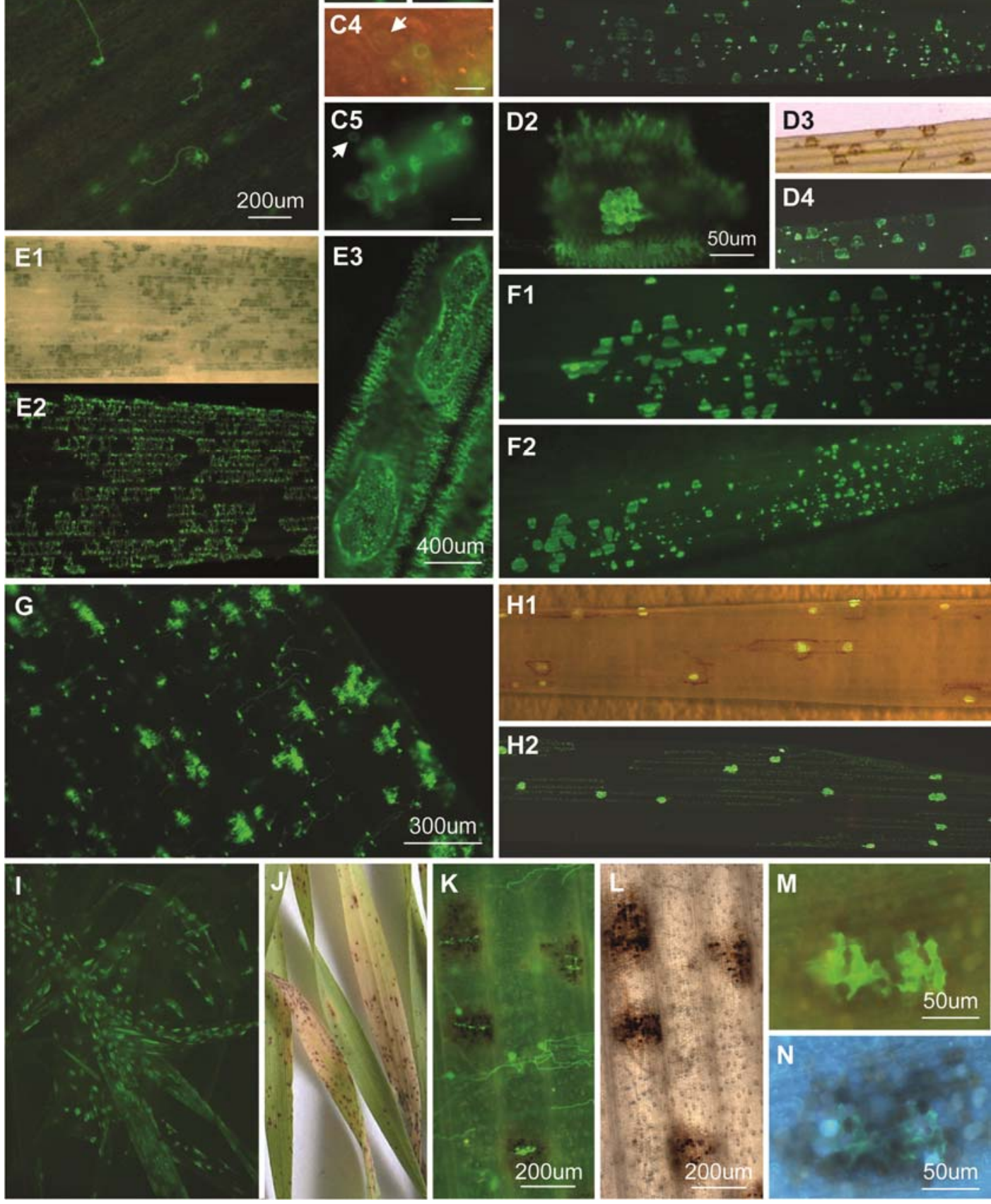
pared with other infection sites. Two exceptions to this generalization were observed. Some members of the BdTr10 group produced small brown lesions that were not associated with large infection sites (described below), while some members of the BdTr8 group, even when uninfected, produced spreading gray lesions.

A strong correlation between the genetic relationship of these accessions and the phenotypes observed upon $P$. graminis $\mathrm{f}$. sp. tritici infection was apparent. All members of the TEK group (Vogel et al. 2009) showed very restricted pathogen development when infected with $P$. graminis f. sp. tritici (Table 1). In contrast many, although not all (e.g., Bd21 and BdTr10), accessions in group 2 allowed extensive pathogen growth and sporulation in some instances, often with all members within a single clade showing very similar phenotypes (Table 1). In some accessions, a clear developmental gradient of NHR to $P$. graminis f. sp. tritici infection was observed, particularly among the BdTr13 group. Here, a basipedal gradient of $P$. graminis f. sp. tritici growth was often observed on single leaves, with a greater frequency of large infection sites being present at the leaf base and a progressively diminishing frequency of large infection sites occurring toward the leaf tip (Fig. 1D1, F1, and F2). This fungal growth pattern reflects the age gradient of leaf cells, suggesting that the youngest leaf cells are less capable of suppressing the growth of the nonadapted pathogen.

\section{P. striiformis f. sp. tritici infection.}

A subgroup of $32 \mathrm{~B}$. distachyon accessions representative of the genetic diversity identified by Vogel and associates (2009) were infected with an Australian P. striiformis f. sp. tritici isolate, $104 \mathrm{E} 137 \mathrm{~A}-$ (Table 1). A largely inverse relationship was observed in infection phenotypes when compared with P. graminis f. sp. tritici infection, with those accessions allowing the most $P$. striiformis f. sp. tritici growth generally being the most restrictive of $P$. graminis f. sp. tritici growth and vice versa. This observation is exemplified by $\mathrm{Bd} 21$, where minimal growth of $P$. graminis f. sp. tritici occurred (Fig. 1C1) but extensive growth of $P$. striiformis $\mathrm{f}$. sp. tritici was observed (Fig. 1B, E1, and E2). The distribution of infection site sizes of each rust species on this accession is shown in Figure 2.

All members of the TEK group that were tested supported extensive $P$. striiformis f. sp. tritici development (Fig. 2, Tek4/ $P$. striiformis f. sp. tritici) but these same accessions were among the most restrictive of $P$. graminis $\mathrm{f}$. sp. tritici growth (Table 1). In contrast, many group 2 accessions (e.g., the BdTr13 group) that allowed extensive $P$. graminis f. sp. tritici development (Fig. 1D1, F1, and F2) were highly restrictive of $P$. striiformis f. sp. tritici growth (Table 1). These data indicate a strong relationship between plant genotype and NHR response to $P$. graminis f. sp. tritici and $P$. striiformis $\mathrm{f}$. $\mathrm{sp}$. tritici. This correlation, although compelling, is not absolute, because some members of group 2 (e.g., Bd21) showed extensive $P$. striiformis f. sp. tritici growth and restricted $P$. graminis f. $\mathrm{sp}$. tritici development, similar to that of the TEK group (Table 1).

For accessions on which extensive $P$. striiformis $\mathrm{f}$. sp. tritici growth was apparent, macroscopic lesions were observed (Fig. $1 \mathrm{E} 1$ and E2), consistent with previous reports of macroscopic stripe rust lesions (Barbieri et al 2012; Draper et al. 2001). Conversely, accessions that severely restricted $P$. striiformis $\mathrm{f}$. sp. tritici growth showed no obvious macroscopic symptoms (not shown). Hence, as observed for $P$. graminis f. sp. tritici, the presence of large lesions on $B$. distachyon upon $P$. striiformis f. sp. tritici infection is indicative of extensive fungal colonization (Fig. 1E1 and E2) rather than an extreme resistance response. Unlike $P$. graminis f. sp. tritici, however, no sporulating pustules were ever produced by the Australian $P$. striiformis f. sp. tritici isolate used in this study on any accession over multiple experiments when grown under glasshouse conditions at $21^{\circ} \mathrm{C}$. However, subsequently, it became apparent that $P$. striiformis $\mathrm{f}$. sp. tritici sporulation did occur on accession Bd21 and TEK4 (other accessions were untested) when the maximum daily temperature was reduced to $18^{\circ} \mathrm{C}$ (Fig. 1E3), which is the first report of $P$. striiformis $\mathrm{f}$. sp. tritici sporulation on this diploid $(2 \mathrm{x}=10)$ species, and consistent with $P$. striiformis sporulation reported on $B$. hybridum (Barberi et al. 2012; Draper et al. 2001). The development of $P$. striiformis $\mathrm{f}$. sp. tritici symptoms on Brachypodium spp. was also substantially delayed when compared with wheat, with symptoms being maximal 3 to 4 weeks postinfection, after which time many leaves began to initiate developmental senescence.

A second subgroup of Brachypodium accessions was infected with a European $P$. striiformis f. sp. tritici isolate, 08/501. Five of these accessions had also been screened with the Australian P. striiformis f. sp. tritici isolate and very similar infection outcomes were observed for both stripe rust pathogen isolates on theses common accessions, indicating little evidence of race specificity. An inverse relationship was also observed for $P$. graminis f. sp. tritici growth and growth of the European $P$. striiformis $\mathrm{f}$. sp. tritici isolate on $\mathrm{Bd} 1-1, \mathrm{Bd} 2-3, \mathrm{Bd} 3-1, \mathrm{Bd} 21$, Bd21-3, and Gaz6 and Gaz4 members of the Koz group. However, this relationship was not apparent among Adi and Kah

Fig. 1. Growth of rust pathogens on B. distachyon. A, Macroscopic symptoms observed on leaves from B. distachyon accession BdTr3b 4 weeks postinoculation (wpi) with Puccinia graminis f. sp. tritici. B, Symptoms present on leaves of Bd21 plants $4 \mathrm{wpi}$ with P. striiformis f. sp. tritici. C, Microscopic analysis of $\mathrm{Bd} 21$ tissue 4 wpi with $P$. graminis $\mathrm{f}$. sp. tritici. C1 shows small P. graminis f. sp. tritici infection sites on the leaf. Most sites consisted of appressoria (C2) and substomatal vesicles with several small infection hyphae (C3). Larger infection sites were also observed (C5) that produced haustoria (C4 and C5 arrowhead). C2/C3 and C4/C5 are the same infection sites, respectively. A 20- $\mu \mathrm{m}$ scale bar is shown in C2 to C5. D, Growth of $P$. graminis f. sp. tritici on B. distachyon accession BdTr13g 4wpi. A mixture of large and small infection sites are apparent (D1), with the largest sites producing urediniospores (D2). Macroscopic symptoms on the leaf (D3, cleared leaf) correlate with large $P$. graminis f. sp. tritici infection sites (D4). D3 and $\mathrm{D} 4$ are the same region of leaf tissue. E, Extensive growth of $P$. striiformis $\mathrm{f}$. sp. tritici on B. distachyon accession Bd21. Obvious macroscopic symptoms are seen on the leaf surface (E1) that correspond to infection hyphae ramification throughout the leaf (E2). When grown under an $18^{\circ} \mathrm{C}$ maximum temperature, P. striiformis f. sp. tritici uredinia were observed (E3). F, Basipedal gradient of $P$. graminis f. sp. tritici growth on leaves from B. distachyon BdTr13 accessions. F1 and F2 show a leaf from accession BdTr13f and BdTr13k, respectively, infected with $P$. graminis f. sp. tritici. A higher frequency of large infection sites is seen at the leaf base (left-hand side of each figure) in each case. A similar gradient of growth is observed in D1 on a BdTr13g leaf infected with $P$. graminis f. sp. tritici. G, Growth of $P$. triticina on $\mathrm{Bd} 214$ wpi. A distribution of infection site sizes is apparent, ranging from small to medium. $\mathbf{H}$, Growth of $P$. graminis f. sp. phalaridis on Bd21 4wpi. Sporulating infection sites shown in H1 are surrounded by macroscopic browning. Extensive ramification of infection hyphae occurs throughout the leaf beneath $P$. graminis $\mathrm{f}$. sp. phalaridis pustules (H2). I, Extensive growth of $P$. graminis $\mathrm{f}$. sp. avena on B. distachyon Bd21 4 wpi. Several heavily infected leaves are shown with extensive growth of infection hyphae and frequent production of sporulating uredinia. J, Macroscopic lesions present on leaves of BdTr10h 4 wpi with P. striiformis f. sp. tritici. K, Small P. graminis f. sp. tritici infection sites present on a leaf from BdTr10h. Spores and spore germ tubes can also be seen on the leaf surface. L, Pigmentation in cells surrounding P. striiformis f. sp. tritici infections shown in K. Note that browning is not associated with rust infection structures on the leaf surface. M, $P$. striiformis f. sp. tritici infection site on leaf tissue of BdTr10h. N, Autofluorescence associated with the P. striiformis f. sp. tritici infection shown in M. All images showing microscopic analysis of rust infection were stained with wheat germ agglutinin conjugated to fluorescein isothiocyanate. 
accessions and most members of the Gaz group, with each accession showing only small amounts of growth of both rust pathogens. These latter groups were not tested with the Australian $P$. striiformis f. sp. tritici isolate.

\section{P. triticina infection.}

B. distachyon accessions $\mathrm{Bd} 21, \mathrm{Bd} 21-3, \mathrm{Bd} 2-3, \mathrm{Bd} T \mathrm{~h} 3$, BdTr10h, BdTr10m, BdTr13g, BdTr13h, TEK4, TEK7, and
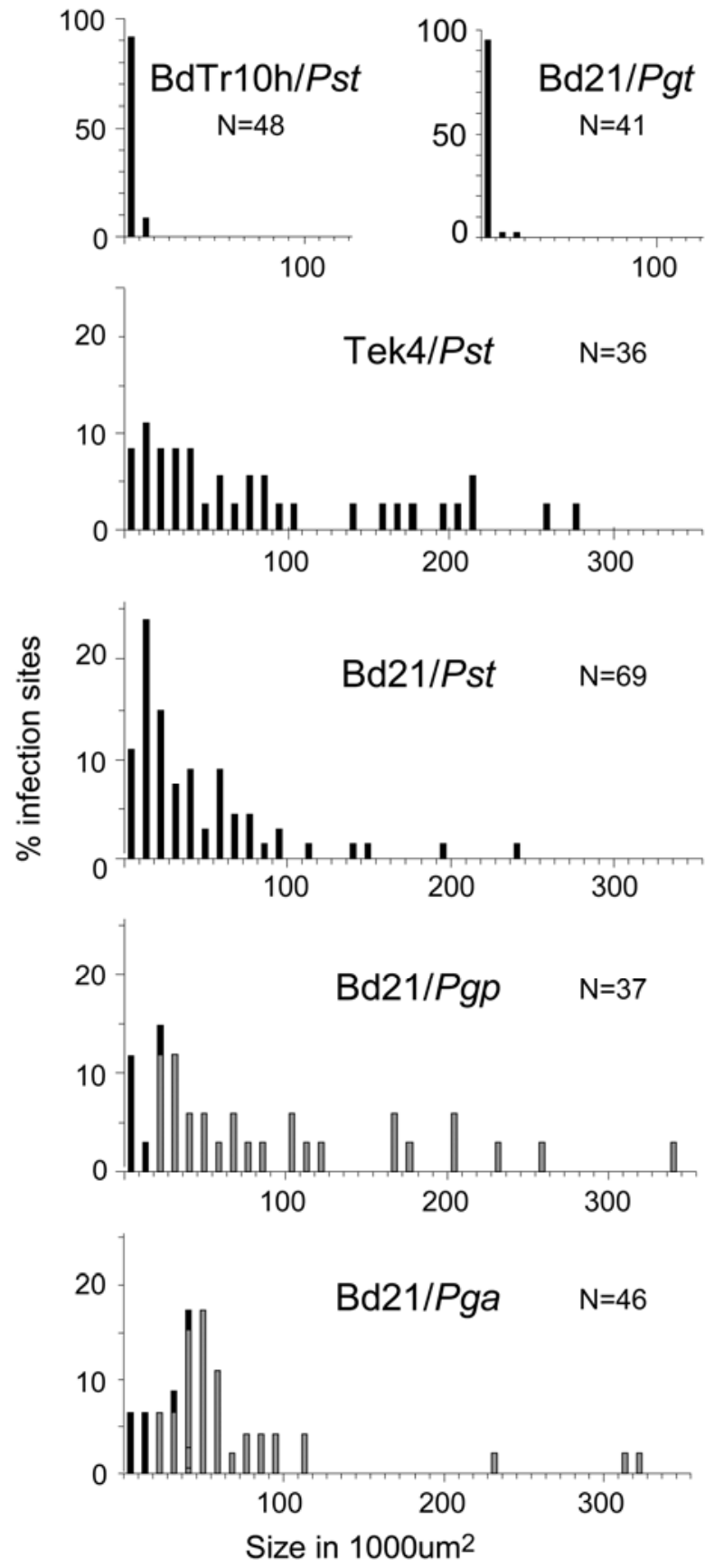

Fig. 2. Distribution of infection site areas of rust pathogens on Brachypodium distachyon accessions. Each graph shows the percent of rust infection sites ( $y$ axis) with a given infection site area in $1,000 \mu \mathrm{m}^{2}$ ( $x$ axis). Infection site areas were determined by measuring microscopically the length and width of each infection site and then calculating the area based upon the assumption that each site is oval in shape. The B. distachyon accession and cereal rust used for infection are indicated on each graph as "accession/abbreviated rust pathogen", as is the number of infection sites measured (N). Infection sites depicted as black bars did not produce rust spores while those depicted as gray bars did sporulate. Note that the $y$ axis has a different scale on the first two graphs compared with the remainder.
TEK12 were infected with $P$. triticina isolate 104-1236(7)11. Unlike $P$. graminis f. sp. tritici and $P$. striiformis $\mathrm{f}$. sp. tritici, this rust pathogen didn't produce as much variation in $B$. distachyon infection phenotypes among this relatively small group of accessions, with obvious macroscopic symptoms absent on all accessions analyzed. Microscopic analysis identified a distribution of $P$. triticina infection sites on each accession which ranged from little more than a substomatal vesicle up to infection sites that encompassed over 100 mesophyll cells, with different-sized infection sites in close juxtaposition (Fig. 1G). The extent of growth of this $P$. triticina isolate was not as pronounced on any accession as was the growth of $P$. graminis f. sp. tritici or $P$. striiformis f. sp. tritici on some of these $B$. distachyon lines.

Infection of Brachypodium spp. with $P$. graminis rusts that have Poeae hosts.

All $140 \mathrm{~B}$. distachyon accessions were inoculated with $P$. graminis f. sp. phalaridis, a stem rust forma specialis that parasitizes Phalaris aquatica (phalaris grass). In contrast to Puccinia graminis f. sp. tritici infection, where the formation of small uredinia was relatively rare on most accessions, $P$. graminis $\mathrm{f}$. $\mathrm{sp}$. phalaridis rust frequently produced sporulating uredinia on most $B$. distachyon accessions, with only a single accession (BdTr7a) not producing pustules. Often associated with these small uredinia was a ring of brown plant tissue surrounding the uredinium but which did not encompass the extensive underlying infection hyphae (Fig. 1, $\mathrm{H} 1$ and $\mathrm{H} 2$ ).

Similar infection was seen with $P$. graminis f. sp. avena, the special form of stem rust pathogen that infects oat, with sporulating uredinia observed on all of the $B$. distachyon accessions examined (Fig. 1I). However, on two accessions, BdTr7a and Bd1-1, uredinia were rare and very small when formed. In contrast, on some accessions, uredinia were up to $1.5 \mathrm{~mm}$ in size, with large numbers of urediniospores produced (Fig. 1I). On cultivars showing significant $P$. graminis $\mathrm{f}$. $\mathrm{sp}$. phalaridis and $P$. graminis f. sp. avena pustule production (e.g., Bd21), a distribution of infection site sizes was observed microscopically with many small infection sites also present (Fig. 2).

These data indicate that $B$. distachyon support more extensive colonization by $P$. graminis rusts that parasitize the family Poeae compared with $P$. graminis $\mathrm{f}$. sp. tritici. $B$. distachyon could even be considered partial hosts of Poeae stem rusts, given that sporulating uredinia occurred on most accessions. For comparative purposes, the median infection site area observed for different rust pathogen species on several different $B$. distachyon accessions is shown (Fig. 3A); these being Bd21, which allows extensive growth of $P$. striiformis f. sp. tritici, $P$. graminis $\mathrm{f}$. $\mathrm{sp}$. avena, and $P$. graminis f. sp. phalaridis but is restrictive of $P$. graminis f. sp. tritici growth; BdTr10h, which is restrictive of $P$. striiformis f. sp. tritici; and TEK4, which allows extensive $P$. striiformis f. sp. tritici growth. In addition, the median infection site area of wheat stem rust pustules that have just erupted on a fully susceptible wheat host is included. Although these latter infection sites on the host plant have not reached full size, they are at least eightfold larger than nonadapted rust growth on B. distachyon. Therefore, those B. distachyon accessions that allowed the most growth of the rust pathogens examined were still significantly restrictive when compared with the fully susceptible host.

\section{The nonhost response to rust pathogen infection.}

For all five rust pathogens described above, cell death around infection sites that resulted in autofluorescence was not common on $B$. distachyon accessions regardless of the extent of fungal growth, indicating that hypersensitive cell death was usually not involved in the NHR response. Even on those 
accessions where autofluorescent cell death was more common, the extent of autofluorescence was often limited to just one or two cells (Fig. 3B). An exception to this generalization occurred with BdTr10h (Fig. 3B), which is further described below.

In contrast, when callose deposition was examined after Brachypodium infection with $P$. graminis f. sp. tritici, $P$. striiformis $\mathrm{f}$. sp. tritici, or $P$. triticina, it was present at most infections sites, regardless of infection site size (Fig. 4A to C). However, an obvious difference appeared to exist in the number of callose-producing cells at different-sized infection sites on the same leaf, with small infection sites appearing to have a proportionally greater number of callose-producing cells compared with large infection sites (Fig. 4A to C).

To further characterize the callose deposition patterns observed, the size of rust infection sites was measured microscopically and the number of callose-producing cells counted at each site. This process was undertaken for $P$. graminis f. sp. tritici infection sites on BdTr13h, P. striiformis f. sp. tritici sites on $\mathrm{Bd} 21$, and $P$. triticina sites on $\mathrm{Bd} 21-3$ and $\mathrm{Bd} 21$. These accessions were chosen due to their propensity to allow the growth of both large and small infection sites of each rust pathogen species. A linear relationship was observed between $\log 2$ of the infection site area versus $\log 2$ of the infection site area divided by the number of callose-producing cells (essentially equivalent to the proportion of noncallose-producing cells) (Fig. 5A).

These data suggest that large rust infection sites on $B$. distachyon increase in size due to an ability to either suppress callose deposition or avoid detection and subsequent callose deposition in some mesophyll cells. Whether this avoidance or suppression is transient or fixed is unknown; however, the absence of callose production in infected cells in the center of large infection sites (i.e., the earliest infected cells) suggest a long-term ability to suppress the callose deposition response (Fig. 4A1 and A2). The absence of callose in some cells at large infection sites does not appear to be due to differential callose turnover because most small infection sites remained surrounded by callose-producing cells for the entire infection period.

Pathogen arrest by callose deposition in the absence of cell death is also a feature of host basal defense mechanisms against adapted pathogens. To compare the relationship between this response for cereal rusts on host and nonhost species, fully susceptible wheat cultivars were infected with the same isolates of $P$. graminis f. sp. tritici, $P$. striiformis f. sp. tritici, and

Fig. 3. A, Median infection site areas of rust pathogen infections and salicylic acid analysis. Median infection site areas shown for Bd21 (21) infected with Puccinia graminis f. sp. tritici, P. striiformis f. sp. tritici, $P$. graminis f. sp. avena, and P. graminis f. sp. phalaridis; $\mathrm{BdTr} 10 \mathrm{~h}(10 \mathrm{~h})$ and TEK4 (T4) infected with $P$. striiformis f. sp. tritici; and Sonora wheat infected with P. graminis f. sp. tritici. This latter measurement on the host plant was taken immediately after pustule eruption and these infection sites would have become significantly larger with increased infection time. B, Analysis of $P$. striiformis $\mathrm{f}$. sp. tritici growth on Brachypodium distachyon accessions. The average number of autofluorescent cells per $P$. striiformis f. sp. tritici infection site is shown. Numbers above each data set indicate the number of infection sites measured while + to ++++ indicates an increasing level of $P$. striiformis f. sp. tritici growth observed. BdTr10h can be seen to produce significantly more autofluorescent cells per infection site $(P<0.05)$ than all other accessions tested. $\mathbf{C}$, Salicylic acid (SA) concentration in uninfected (gray bars) and $P$. graminis f. sp. triticiinfected (white bars) leaf tissue of $B$. distachyon isolates TEK4, Bd21, and BdTr3b. Tissue was harvested 3 days postinoculation. No significant difference in SA concentration was observed between infected and uninfected tissue of the same $B$. distachyon accession. A highly significant difference $(t$ test, $P<0.05)$ in SA concentration was observed between pairwise comparisons of Bd21/TEK4 and Bd21/BdTr3b but not TEK4/ BdTr3b. Standard deviations are indicated.
$P$. triticina rust used to infect $B$. distachyon. Wheat leaves were harvested from these susceptible cultivars after pathogen sporulation had occurred. Microscopic examination indicated that the vast majority of rust infection sites had successfully sporulated. However, occasional infection sites were present that did not manage to sporulate and were significantly smaller
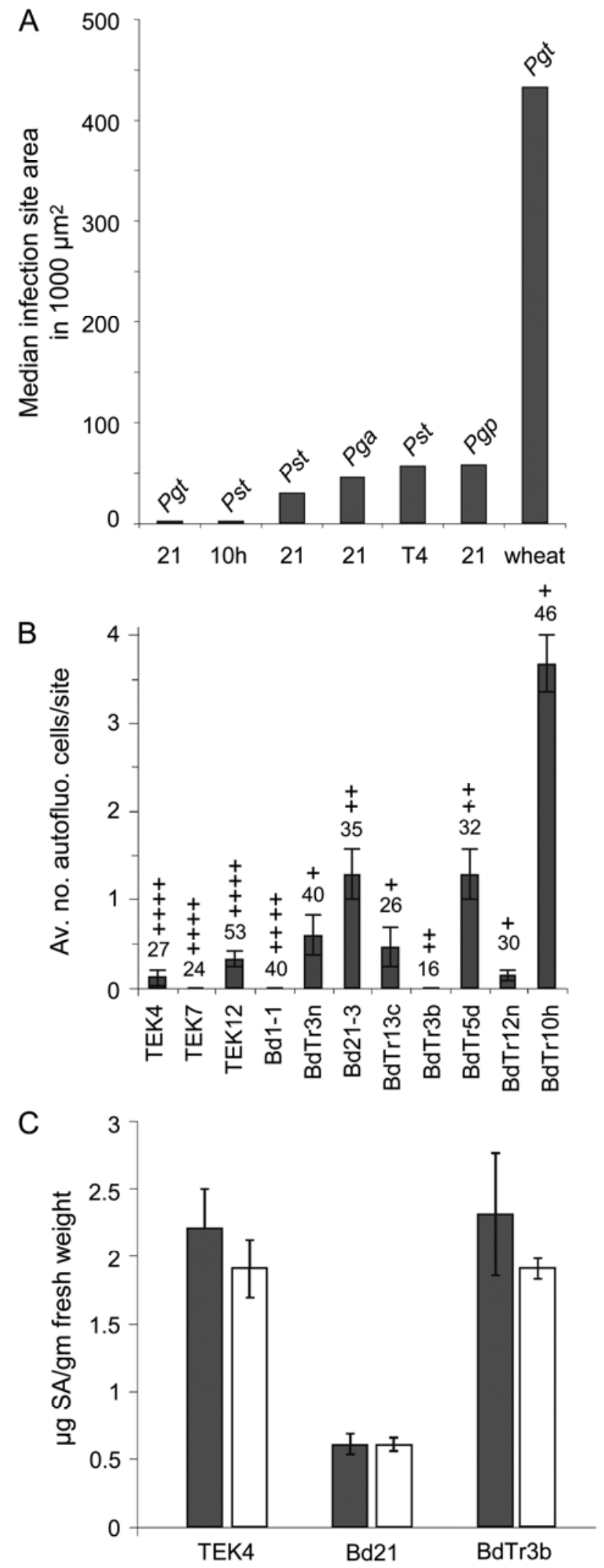
in size than most sporulating infection sites (Fig. 4F1). These smaller sites varied in size, which presumably reflects the point in development when further growth was prevented by basal resistance. When infection site areas and number of callose-producing cells were quantified at these unsuccessful infection sites (Fig. 4F1 and F2), a very similar relationship was observed on wheat compared with the $B$. distachyon nonhost (Fig. 5B). These data suggest that similar mechanisms prevent rust pathogen growth during wheat basal defense and the $B$. distachyon NHR response.

No correlation between the presence of rust haustoria and callose deposition was observed, with haustorium-containing
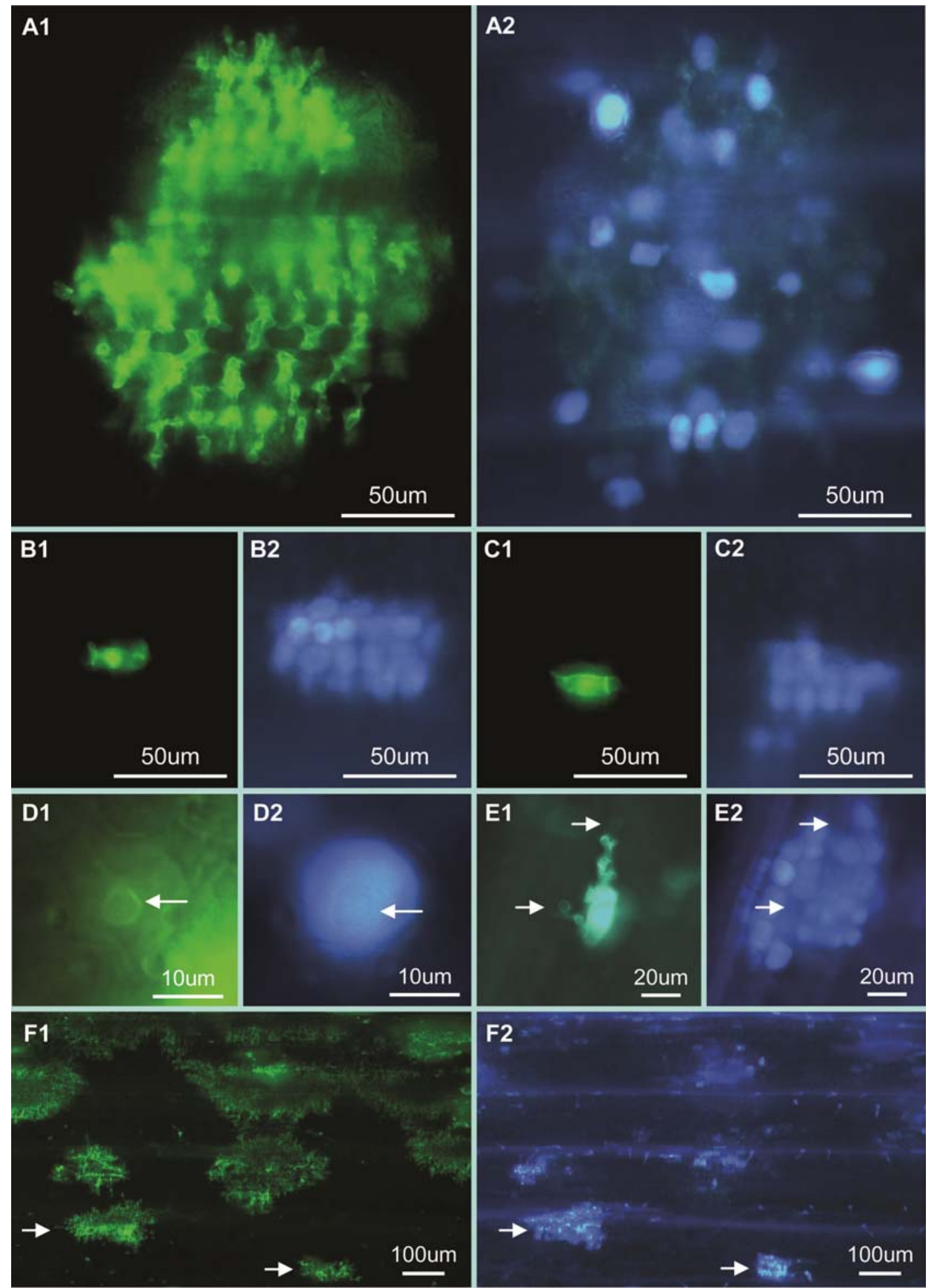

Fig. 4. Callose deposition upon rust pathogen infection. A to C, Large (A1) and small (B1 and C1) Puccinia graminis f. sp. tritici infection sites present on leaves of Brachypodium distachyon accession BdTr13h. Callose-producing cells at each infection site are shown in A2, B2, and C2, respectively. D, P. graminis f. sp. tritici haustorium (D1, marked with an arrow) present in a callose-producing BdTr13h cell (D2). E, Two P. graminis f. sp. tritici haustoria (E1, marked with arrows) present in non-callose producing BdTr13h cells. Other mesophyll cells surrounding this infection site do not contain haustoria but produce callose. F, P. triticina-infected wheat leaf tissue from 'McKellar' is shown in F1. Two small infection sites on this susceptible plant (marked with arrows) show proportionally greater callose deposition compared with surrounding large infection sites (F2). 
cells showing both callose deposition and callose absence at infection sites on both wheat (not shown) and B. distachyon (Fig. 4D and E) for all three wheat pathogen species. Small infection sites that did not develop haustoria on $B$. distachyon (i.e., little more than a substomatal vesicle) were often surrounded by mesophyll cells containing callose (Fig. 4B and C). The activation of a defense response in the absence of haustoria at these infection sites suggests that recognition of the nonadpated pathogen is mediated either by PAMP molecules or, alternatively, from yet-to-be-identified effectors secreted from infection hyphae or substomatal vesicles.

To determine the role of SA accumulation in the $B$. distachyon NHR response to $P$. graminis $\mathrm{f}$. sp. tritici, two $B$. distachyon lines were selected that were restrictive of $P$. graminis $\mathrm{f}$. sp. tritici growth (Bd21 and TEK4) and one line that allowed extensive $P$. graminis f. sp. tritici growth (BdTr3b). At minimum, three pots were infected with $P$. graminis f. sp. tritici and a similar number of pots left uninfected. SA concentration was determined per gram of tissue harvested from each pot and values pooled for identical treatments. From these experiments, no increase in SA accumulation was observed in any $B$. distachyon line in response to $P$. graminis $\mathrm{f}$. sp. tritici infection (Fig. 3C). However, a fourfold difference in SA content was observed between $\mathrm{Bd} 21$ and the remaining two lines that did not correlate with the extent of rust growth observed on these plants (Fig. 3C). Similar variation in SA content has been observed among different rice lines (Raskin et al. 1990; Silverman et al. 1995).

\section{The BdTr10 group is atypical.}

The BdTr10 group and accession Gaz5 appeared atypical upon rust infection for several reasons. For most other accessions, the presence of macroscopic lesions upon infection with either $P$. graminis f. sp. tritici or $P$. striiformis f. sp. tritici invariably correlated with large underlying rust infection sites. In contrast, upon infection with either of these two rust pathogen species, the BdTr10 group and Gaz5 produced numerous small lesions on the leaf surface (Fig. 1J) which, upon microscopic examination, corresponded to small infection sites (Fig. 1K and $\mathrm{L}$ ). These macroscopic lesions were due to the accumula- tion of brown pigment in mesophyll cells surrounding the infection site (Fig. 1L). Among the BdTr10 group, this observation was most pronounced on BdTR10h, BdTr10m, and BdTr10d, with the remaining accessions tending to show less obvious phenotypes.

In addition, unlike other $B$. distachyon accessions, infection sites on BdTr10h were almost always accompanied by autofluorescent cell death (Fig. 1M and N), with a significantly greater average number of autofluorescent cells per infection site (Fig. 3B) (Other accessions in the BdTr10 group were not examined in detail for autofluorescence.) The presence of brown pigment in autofluorescent cells tended to suppress the fluorescence, indicating that this pigment and the fluorescent phenolic compounds localized in the plant cell wall after death were different (Fig. 1M and N). Large rust infection sites were rare on these accessions but were observed occasionally. Only a proportion of small infection sites resulted in lesion formation (approximately half), with many similar-sized infection sites producing no macroscopic symptoms. Therefore, a significant phenotypic difference was apparent in these lines relative to all other accessions in response to $P$. graminis f. sp. tritici and $P$. striiformis f. sp. tritici infection.

However, BdTr10 lines and Gaz5, like most B. distachyon accessions, allowed more extensive growth of both $P$. graminis f. sp. avena and $P$. graminis f. sp. phalaridis, with frequent, small sporulating uredinia produced. In contrast, growth of $P$. triticina was modest on BdTr10h and BdTr10m but infection sites were not associated with pigmentation of adjacent plant cells. Therefore, the atypical response of the BdTr10 group to $P$. graminis f. $\mathrm{sp}$. tritici and $P$. striiformis $\mathrm{f}$. $\mathrm{sp}$. tritici is unique to these two rust pathogens and again demonstrates that the genetically defined NHR outcome is dependent upon both the $B$. distachyon genotype and rust genotype or species.

\section{Inheritance of the NHR response \\ to $P$. striiformis f. sp. tritici.}

To determine the heritability of NHR phenotypes among $B$. distachyon accessions, two families were produced by crossing $B$. distachyon lines that showed differential infection phenotypes. The first cross was produced between BdTr13k and

Table 1. Inverse relationship between Puccinia striiformis f. sp. tritici and P. graminis f. sp. tritici infection site sizes (ifs) on Brachypodium distachyon accessions

\begin{tabular}{llcl}
\hline Accession & Group & P. striiformis f. sp. tritici 104E137A-growth & P. graminis f. sp. tritici growth \\
\hline BdTr1a & 2 & Very small ifs & Large ifs \\
BdTr1c & 2 & Very small ifs & Large ifs \\
Bd2-3 & 2 & Very small ifs & Pustules \\
BdTr3b & 2 & Small ifs & Pustules \\
BdTr3c & 2 & Very small ifs & Pustules \\
BdTr3n & 2 & Very small ifs & Large ifs \\
BdTr5b & Very small ifs & Pustules \\
BdTr5d & Small ifs & medium ifs \\
BdTr9h & 2 & Very small ifs & Pustules \\
BdTr9i & 2 & Very small ifs & Pustules \\
BdTr9k & 2 & Very small ifs & Large ifs \\
BdTr13c & 2 & Very small ifs & medium ifs \\
BdTr13g & 2 & Small ifs & Pustules \\
BdTr13h & 2 & Very small ifs & Pustules \\
Bd21 & 2 & Large ifs & Very small ifs \\
BdTr12a & 2 & medium ifs & Very small ifs \\
BdTr10d & 2 & Very small ifs & Very small ifs \\
BdTr10h & 2 & Very small ifs & Small ifs \\
BdTr10m & 2 & Very small ifs & Very small ifs \\
TEK4 & 2 & Large ifs & Very small ifs \\
TEK7 & TEK & Large ifs & Very small ifs \\
TEK12 & TEK & Large ifs & Very small ifs \\
Bd1-1 & TEK & Large ifs & Small ifs \\
BdTr8a & TEK & Large ifs & Small ifs \\
BdTr8m & TEK & Large ifs & Small ifs \\
\hline
\end{tabular}


$\mathrm{Bd} 21$ while the second cross was produced between BdTr10h and TEK4. Both families were expected to segregate for NHR phenotypes to $P$. striiformis f. sp. tritici, given the phenotypes of each parent described above. B. distachyon is inherently difficult plant species to cross; hence, only a single F1 plant was obtained for each cross from many attempts. The F1 status of each plant was confirmed by the inheritance of restriction fragment length polymorphism markers from each parent and the subsequent segregation of these markers among F2 progeny (Fig. 6).

Seedlings from the F4 generation of the BdTr13k $\times \mathrm{Bd} 21$ family were infected with $P$. striiformis f. sp. tritici isolate 104 E137 A- (with an $18^{\circ} \mathrm{C}$ maximum day temperature) and obvi-
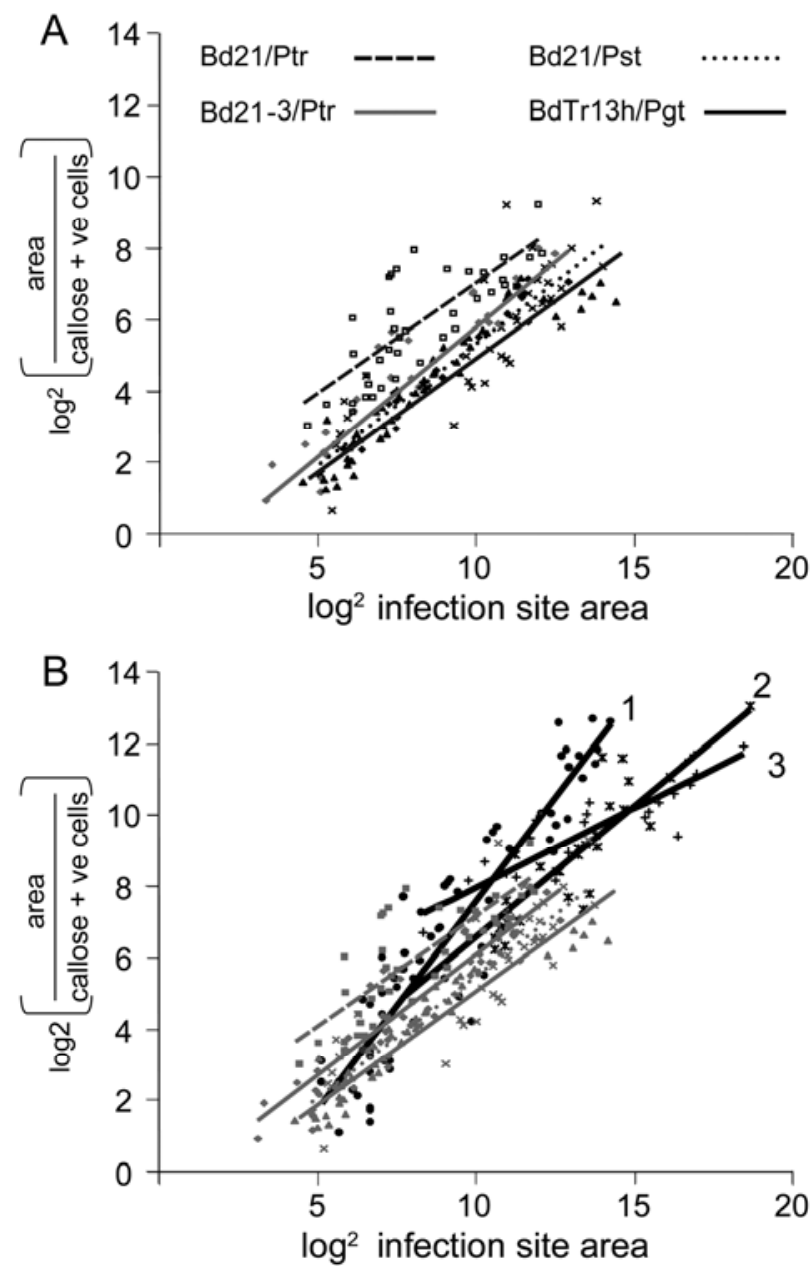

Fig. 5. Relationship between the frequency of callose-producing cells and rust pathogen infection site area. A, Graph $\left(\log ^{2}\right)$ showing cereal rust infection site area ( $x$ axis) relative to the infection site area divided by the number of callose-producing cells at each infection site ( $y$ axis). A small Y value indicates that proportionally more cells at a given infection site produced callose while a large $\mathrm{Y}$ value indicates that much fewer cells produced callose at that infection site relative to its area. For each Brachypodium distachyon accession-rust pathogen interaction, it can be seen that there are proportionally fewer callose-producing cells as infection sites become progressively larger. Measurements for $\mathrm{Bd} 21 /$ Puccinia triticina are indicated by squares, for $\mathrm{Bd} 21-3 / P$. triticina by diamonds, for $\mathrm{Bd} 21 / P$. striiformis $\mathrm{f}$. sp. tritici by $\mathrm{Xs}$, and for $\mathrm{BdTr} 13 \mathrm{~h} / P$. graminis $\mathrm{f}$. sp. tritici by triangles. The line of best fit for each dataset is indicated. B, The same graph shown in A, with measurements superimposed for 'McKellar' wheat infected with $P$. triticina (black circles), 'Sonora' wheat infected with $P$. graminis f. sp. tritici (black diamonds), and 'Morocco' wheat infected with $P$. striiformis f. sp. tritici (black crosses). The line of best fit for these datasets are indicated and labeled 1 to 3, respectively. All B. distachyon data are shown in gray and are identical to those shown in A, while all wheat data are shown in black. ous differences in $P$. striiformis f. sp. tritici infection phenotypes were observed among the $316 \mathrm{~F} 4$ plants tested. In this experiment, two F4 seedlings were infected from each of 158 F3 lines. Plants were readily classified into either of two groups.

Table 2. Segregation of Puccinia striiformis f. sp. tritici infection phenotypes among F4 progeny of selected BdTr13k $\times$ Bd21 F3 lines

\begin{tabular}{lccc}
\hline F3 line & $\begin{array}{c}\text { Number of F4 } \\
\text { progeny tested }\end{array}$ & $\begin{array}{c}\text { Immune } \\
\text { plants }\end{array}$ & $\begin{array}{c}\text { Extensive } \\
\text { P. striiformis f. sp. } \\
\text { tritici growth }\end{array}$ \\
\hline 7 & 19 & 15 & 4 \\
43 & 15 & 13 & 2 \\
56 & 20 & 15 & 5 \\
83 & 9 & 5 & 4 \\
236 & 20 & 19 & 1 \\
256 & 12 & 9 & 3 \\
\hline
\end{tabular}
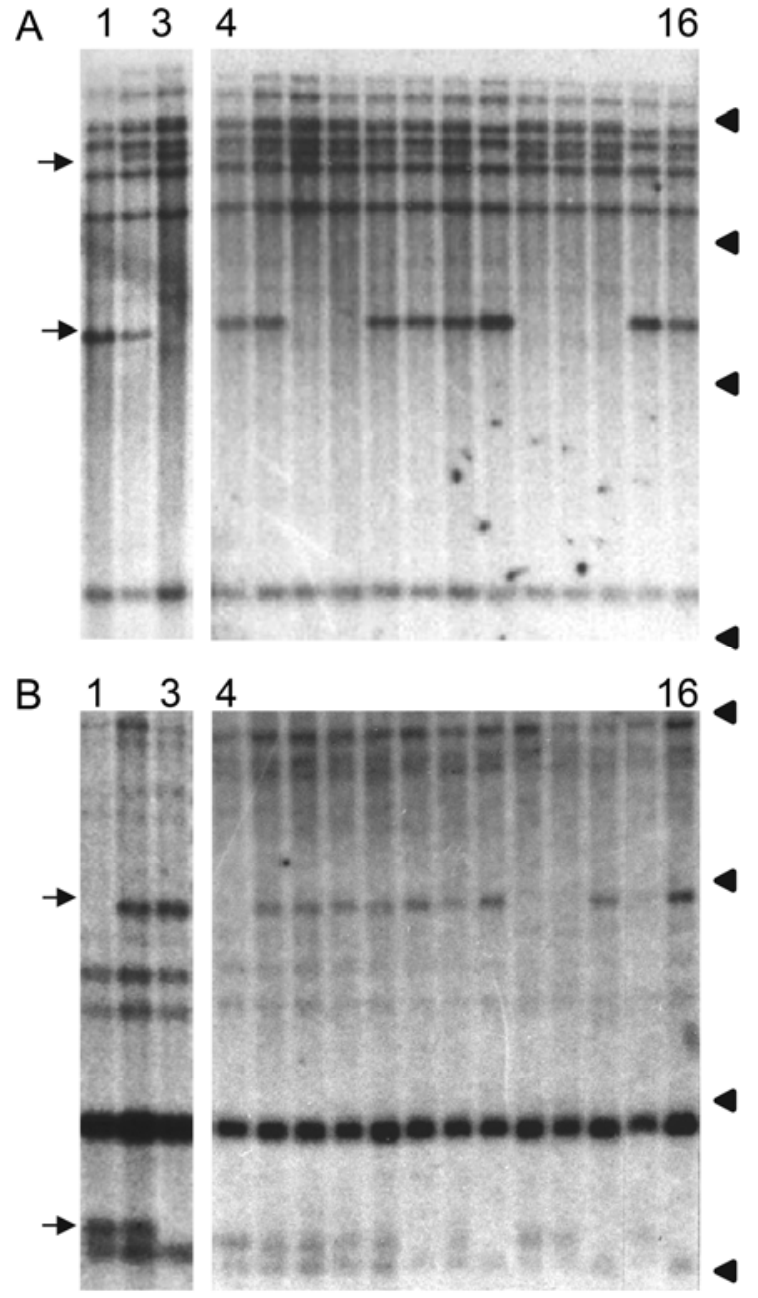

Fig. 6. A, Restriction fragment length polymorphism (RFLP) analysis of Brachypodium distachyon families. DNA blot analysis of $B$. distachyon DNAs restricted with BamHI. Total DNAs were extracted from lane 1, BdTr13k; lane 2, an F1 plant produced from crossing BdTr13k and Bd21; lane 3, Bd21; and lanes 4 to $16,13 \mathrm{~F} 2$ plants derived from the F1 plant. RFLP bands unique to each parent DNA and which segregate in the F2 progeny are highlighted with arrows. B, RFLP analysis of lanes 4 to 16, DNAs from $13 \mathrm{~F} 2$ progeny derived from lane 2, an F1 plant produced by crossing lane 1, BdTr10h, with lane 3, TEK4. DNAs were restricted with XhoI and transferred to nylon membranes. RFLP unique to each parent and which segregate among F2 progeny are indicated with arrows on the left-hand side of the image. Membranes in both panels were hybridized with a probe encoding nucleotides 3,605 to 4,161 of an Oryza sativa phenylalanine ammonia lyase gene (GenBank accession X87946). Arrowheads on the right-hand side of each panel indicate molecular weight mobilities of $12,5,3$, and $2 \mathrm{~kb}$, respectively. 
In total, 88 F4 seedlings showed extensive $P$. striiformis f. sp. tritici symptoms on the leaf, including sporulation in some instances (Supplementary Fig. S1) similar to the Bd21 parent, while 228 plants showed immunity, as did the BdTr13k parent. Little evidence of intermediate phenotypes was observed. Among the 158 F3 lines tested, in 107 cases, both F4 seedlings were immune; in 37 cases, both F4 seedlings showed obvious P. striiformis f. sp. tritici symptoms; whereas, for 14 F3 lines, one F4 seedling showed immunity while the other showed obvious $P$. striiformis f. sp. tritici symptoms. From 6 of the 14 F3 lines in which segregation of $P$. striiformis f. sp. tritici immunity was observed, additional F4 seedlings were tested. In each small F4 family analyzed, segregation was again observed for either immunity or extensive $P$. striiformis f. sp. tritici symptom development, with no intermediate phenotypes again observed (Table 2).

Microscopic analysis of all 316 F4 plants described above confirmed that each plant was heavily challenged with $P$. striiformis f. sp. tritici and that immune plants contained many small $P$. striiformis f. sp. tritici infection sites consisting of substomatal vesicles, infection hyphae, and haustoria. In contrast, F4 plants with obvious macroscopic symptoms showed extensive $P$. striiformis f. sp. tritici growth, with frequent production of uredinia upon microscopic examination. These latter infection sites again corresponded precisely with macroscopic lesions.

This phenotypic data is not consistent with immunity to $P$. striiformis f. sp. tritici infection being conferred by many genes with small additive effects because intermediate infection phenotypes were not observed among these plants. Rather, immunity appears to be a trait with a relatively simple mode of inheritance. The segregation ratios observed in this F4 family are most consistent with a two gene model, with one dominant and recessive gene each independently conferring immunity; however, additional genetic analyses are required to confirm this gene model.

Infection with $P$. striiformis f. sp. tritici isolate 104 E137 Awas also undertaken on $213 \mathrm{~F} 2$ seedlings derived from the BdTr10h $\times$ TEK 4 cross. In this case, three phenotypes were observed macroscopically. In all, 115 seedlings were immune; 44 seedlings showed very small brown lesions, as did the BdTr10h parent; while 54 seedlings showed extensive $P$. striiformis $\mathrm{f}$. sp. tritici infection symptoms, with sporulation at some infection sites, as did the TEK4 parent. Microscopic analysis of plants showing either immunity or having small brown lesions on the leaf surface indicated that both groups contained small $P$. striiformis $\mathrm{f}$. sp. tritici infection sites similar in size to the BdTr10h parent, whereas extensive $P$. striiformis f. sp. tritici growth was observed on plants that showed large macroscopic symptoms. In this family, little evidence of intermediate amounts of $P$. striiformis $\mathrm{f}$. $\mathrm{sp}$. tritici growth relative to the parental lines was also observed. These data are consistent with a single, dominant gene present in the BdTr10h parent severely restricting $P$. striiformis $\mathrm{f}$. $\mathrm{sp}$. tritici growth relative to the TEK4 parent (i.e., 159 plants with restricted growth versus 54 plants with extensive growth, $\chi^{2} P=0.905$ ).

As described above, the BdTr10 group is atypical in that small brown lesions are often associated with both $P$. striiformis f. sp. tritici and $P$. graminis f. sp. tritici infection sites even though BdTr10 accession are highly restrictive of growth by both of these nonadapted rust pathogens (Fig. $1 \mathrm{~J}$ to $\mathrm{N}$ ). In most other $B$. distachyon accessions, the presence of macroscopic symptoms invariably corresponds to extensive $P$. striiformis $\mathrm{f}$. sp. tritici or $P$. graminis f. sp. tritici growth. Interestingly, the $159 \mathrm{BdTr} 10 \mathrm{~h} \times \mathrm{TEK} 4 \mathrm{~F} 2$ plants that showed extreme inhibition of $P$. striiformis $\mathrm{f}$. sp. tritici growth segregated for this brown lesion trait, with this segregation consistent with a single, recessive gene conferring the browning response (115 immune versus 44 small brown lesions, $\left.\chi^{2} P=0.606\right)$. These data suggest that, segregating independently of extreme $P$. striiformis f. sp. tritici resistance, a second gene is conferring browning, but this latter gene is not required for immunity. It is difficult to determine whether this brown-lesion phenotype is also apparent in the remaining F2 plant group that showed extensive $P$. striiformis $\mathrm{f}$. sp. tritici growth, given the severity of the symptoms associated with these infection sites.

\section{DISCUSSION}

These data demonstrate phenotypic variation among different $B$. distachyon accessions in the NHR response to infection by several rust pathogens. These phenotypes are often conserved between genetically related accessions and also dependent upon the rust pathogen used. These observations are exemplified by the inverse relationship between $P$. graminis f. sp. tritici and $P$. striiformis f. sp. tritici growth on the TEK group and many group 2 accessions, with $P$. striiformis $\mathrm{f}$. sp. tritici growth most pronounced on the former group and $P$. graminis f. sp. tritici sporulation occurring only on the latter. Similarly, the atypical response of the BdTr10 group, typified by increased autofluorescent cell death and pigmentation occurring at small infection sites, is specific to $P$. graminis f. sp. tritici and $P$. striiformis $\mathrm{f}$. sp. tritici infection but is not apparent in response to challenge by $P$. triticina, $P$. graminis f. sp. avena, or $P$. graminis f. sp. phalaridis. Therefore, the NHR response to cereal rust growth is dependent upon both the nonhost genotype and the rust pathogen species.

Microscopic analyses indicated that callose deposition during the NHR response could be induced in adjacent mesophyll cells of $B$. distachyon by as little as a rust substomatal vesicle (Fig. 4D and E). Given the absence of haustoria and haustorial effectors (Rafiqi et al. 2012) at these sites, the defense response, presumably, is PAMP triggered. In addition, a similar relationship was observed between callose production and infection site area for both the $B$. distachyon NHR response and wheat basal defense to all three wheat rust pathogen species, with the latter host response also likely based upon PAMP-triggered immunity (Jones and Dangl 2006).

The observation that larger rust infection sites contain proportionally fewer $B$. distachyon cells producing callose is consistent with these infection sites having a transient ability to suppress or evade the NHR response. The absence of callose in some cells located in the middle of large infection sites which have been infected for 4 weeks suggests that suppression of callose deposition in these cells may be irreversible. Why cells in juxtaposition at the same infection site show such variation in callose deposition patterns is unknown and highlights the remarkably cell-autonomous nature of the NHR response at these larger infection sites.

Variation was also observed for rust pathogen infection site size on the same leaf even though clonal spores are used for the infection. Similar variation in infection outcomes is also apparent for these same rust species on susceptible hosts, with a small proportion of infection sites failing to circumvent basal resistance. A consequence of these differential outcomes is that, in both nonhost and host interactions, a continuum of infection site sizes is observed. It is the range and median of this distribution that distinguishes host and nonhost interactions to rust pathogen infections and also explains the macroscopic variation in the nonhost response observed among different $B$. distachyon lines.

Plant cell death that resulted in autofluorescence was neither common nor extensive at rust infection sites on B. distachyon, whereas callose deposition was frequently observed. These observations are similar to cereal rust infection of rice (Ayliffe et 
al. 2011). In spite of the possibly very different evolutionary history of these two plant species with rust pathogens, they respond with apparently similar NHR responses. Rice may have evolved in the absence of rust pathogens (Leppik 1961; Wahl et al. 1984), whereas B. distachyon, being indigenous to the Mediterranean region (Filiz et al. 2009; Garvin et al. 2008), has co-evolved with the rust pathogens of cereal progenitors and is parasitized by rust species.

Although apparently similar NHR responses occur on rice (Ayliffe et al. 2011) and B. distachyon upon infection with nonadapted rust pathogens, the extent of rust growth is far greater on $B$. distachyon. This observation is unsurprising given that $B$. distachyon is believed to have diverged from the Triticeae family 35 to 40 million years ago (Bossolini et al. 2007) whereas rice diverged approximately 50 million years ago (Paterson et al. 2004). The greater colonization of B. distachyon by stem rust pathogens that parasitize the Poeae family $(P$. graminis f. sp. phalaridis and $P$. graminis f. sp. avena [this study] and $P$. graminis ff. spp. lolii and phlei-pratensis [Figueroa et al. 2013]) suggests that these plant species may be more closely related to the Poeae than the Triticeae family, in spite of apparently equidistant phylogenetic relationships (Song et al. 2007). Arguably, the B. distachyon-P. graminis f. sp. tritici interaction is a true nonhost interaction while $B$. distachyon is a partial host for stem rust pathogens of the Poeae family, given the formation of sporulating uredinia on most accessions examined.

Ultimately, an understanding of the NHR response of $B$. distachyon to rust pathogens can only be resolved by isolating the $B$. distachyon genes that confer differential rust infection phenotypes. The microscopic phenotypic differences we have reported in this manuscript provide an entry point for isolating these genes and, based upon this information, two $B$. distachyon mapping families have been produced from parents that show differential NHR responses to rust pathogen infection. Analysis of $P$. striiformis f. sp. tritici infection of progeny from these families demonstrates that the different NHR phenotypes present in the parents are clearly heritable. Remarkably, these phenotypic differences do not appear to be under complex, additive genetic effects, because only parental phenotypes were observed to segregate in progeny upon $P$. striiformis f. sp. tritici infection. Preliminary genetic analyses indicate potentially simple inheritance of these phenotypes, with apparent single gene segregation observed in one family. These data demonstrate that $B$. distachyon will be a powerful model system for elucidating the molecular basis of NHR to rust pathogens of important cereal crop species.

\section{MATERIALS AND METHODS}

Plant and fungal material.

Seed of B. distachyon plants were provided by J. Vogel via I. Wilson. These accessions, most of which are described by Vogel and associates (2009), are all diploid and hence bona fide members of the $B$. distachyon species (Catalan et al. 2012). Plants were grown in a soil/compost (1:1) mixture at $21^{\circ} \mathrm{C}$ for $16 \mathrm{~h}$ of light and $16^{\circ} \mathrm{C}$ for $8 \mathrm{~h}$ of darkness in a glasshouse supplemented with additional lighting. For some accessions, seed was stratified at $4^{\circ} \mathrm{C}$ for 1 week to enhance germination. For rust inoculations, plants were placed in a humid chamber and rust spores applied as an aerosol. Spores were mixed with an equal volume of talc powder to assist in obtaining a more uniform inoculation. Tissue from rust-infected $B$. distachyon plants were harvested 3 to 4 weeks postinfection for microscopy analyses. Rust isolates were propagated on hosts by inoculation of seedlings at the three-leaf stage with an aqueous suspension of rust urediniospores. Inoculated seed- lings were incubated overnight at $16^{\circ} \mathrm{C}$ in a humid chamber and, subsequently, transferred to the glasshouse for postinoculation rust development. The five rust pathogens used in this study were $P$. graminis f. sp. tritici Plant Breeding Institute (PBI) accession number 690822; $P$. graminis $\mathrm{f}$. sp. avenae PBI accession number 962508; P. graminis f. sp. phalaridis PBI accession number 01197; $P$. striiformis f. sp. tritici PBI accession number 821559 , and $P$. triticina PBI accession number 89172. All of these isolates are maintained in liquid nitrogen at the PBI Cobbitty.

\section{Microscopy of rust infected plant tissue.}

All rust-infected plant tissues were stained as described by Ayliffe and associates (2011). Briefly, harvested leaf tissue was autoclaved in $1 \mathrm{M} \mathrm{KOH}$, then neutralized in $50 \mathrm{mM}$ Tris, $\mathrm{pH}$ 7.0. Tissue was then stained with wheat germ agglutinin conjugated to fluorescein isothiocyanate (WGA-FITC) at 20 $\mu \mathrm{g} / \mathrm{ml}$ (Sigma-Aldrich, St. Louis) and viewed under blue light. Autofluorescence was examined in the same tissue under UV light.

\section{Analysis of callose deposition.}

Leaf tissue that had been cleared and stained with WGAFITC as described above was subsequently stained with aniline blue fluorochrome (Biosupplies, Bundoora, Australia) and examined under UV light to enable callose-producing cells to be detected. This double staining enabled rust infection structures to be observed under blue light and callose-producing plant cells at the same site to be observed under UV light. Each rust infection site was photographed and the number of callose-producing cells was counted. The area of rust infection was calculated for each photograph by measuring the maximum width (W) and length (L) of rust growth using the polyline facility of the AnalySIS Life Science Professional program. The rust infection was then assumed to be oval in shape and the area calculated as $\mathrm{L} / 2 \times \mathrm{W} / 2 \times 3.14$. Each infection site area was then divided by the number of callose-producing cells at the site to generate a value that represents the infection site area per callose-producing cell. A large value indicates that relatively few mesophyll cells are producing callose at the infection site whereas a small value indicates extensive callose deposition.

\section{SA analysis.}

$B$. distachyon seedlings were grown to the fifth-leaf stage and then infected with $P$. graminis f. sp. tritici. Three days postinfection, tissue was harvested from infected pots and uninfected control pots and SA content determined per gram fresh weight of tissue, essentially as previously described (Ayliffe et al. 2011). A minimum of three replicates was used for each $B$. distachyon genotype.

\section{ACKNOWLEDGMENTS}

M. J. Moscou was supported by a fellowship from the Human Frontier Science Program and Gatsby Charitable Foundation. We thank the Two Blades Foundation and Australian Grains Research and Development Corporation for financial support; J. Vogel and I. Wilson for providing $B$. distachyon accessions; R. Devilla and P. Wallace for SA analyses; and M. Soliveres, S. Chakraborty, A. Hubbard, and R. Bayles for technical support.

\section{LITERATURE CITED}

Ayliffe, M., Devilla, R., Mago, R., White, R., Talbot, M., Pryor, A., and Leung, H. 2011. Non-host resistance of rice to rust pathogens. Mol. Plant-Microbe Interact. 24:1143-1155.

Barbieri, M., Marcel, T. C., and Niks, R. E. 2011. Host status of false brome grass to the leaf rust fungus Puccinia brachypodii and the stripe 
rust fungus $P$. striiformis. Plant Dis. 95:1339-1345.

Barbieri, M., Marcel, T. C., Niks, R. E., Francia, E., Pasquariello M., Mazzamurro, V., Garvin, D. F., and Pecchioni, N. 2012. QTLs for resistance to the false brome rust Puccinia brachypodii in the model grass Brachypodium distachyon L. Genome 55:152-163.

Bossolini, E., Wicker, T., Knobel, P. A., and Keller, B. 2007. Comparison of orthologous loci from small grass genomes Brachypodium and rice: Implications for wheat genomics and grass genome annotation. Plant $\mathbf{J}$. 49:704-717.

Catalan, P., Muller, J., Hasterok, R., Jenkins, G., Mur, L. A. J., Langdon, T., Betekhtin, A., Siwinska, D., Pimmentel, M., and Lopez-Alvarez, D. 2012. Evolution and taxonomic split of the model grass Brachypodium distachyon. Ann. Bot. 109:385-405.

Collins, N. C., Thordal-Christensen, H., Lipka, V., Bau, S., Kombrink, E., Qui, J. L., Huckelhoven, R., Stein, M., Freialdenhoven, A., Somerville, S. C., and Schulze-Lefert, P. 2003. SNARE-protein-mediated disease resistance at the plant cell wall. Nature 425:973-977.

Draper, J., Mur, L. A. J., Jenkins, G., Ghosh-Biswas, G. C., Bablak, P., Hasterok, R. M., and Routledge, P. M. 2001. Brachypodium distachyon. A new model system for functional genomics in grasses. Plant Physiol. 127:1539-1555.

Fan, J., and Doerner, P. 2012. Genetic and molecular basis of nonhost disease resistance: Complex, yes: Silver bullet, no. Curr. Opin. Plant Biol. 15:400-406.

Figueroa, M., Alderman, S., Garvin, D. F., and Pfender, W. F. 2013. Infection of Brachypodium distachyon by formae speciales of Puccinia graminis: Early infection events and host-pathogen incompatibility. PLoS One 8:e56857.

Filiz, E., Ozdemir, B. S., Budak, F., Vogel, J. P., Tuna, M., and Budal, H. 2009. Molecular, morphological, and cytological analysis of diverse Brachypodium distachyon inbred lines. Genome 52:876-890.

Garvin, D. F., Gu, Y.-Q., Hasterok, R., Hazen, S. P., Jenkins, G., Mockler, T. C., Mur, L. A. J., and Vogel, J. P. 2008. Development of genetic and genomic research resources for Brachypodium distachyon, a new model system for grass crop research. Crop Sci. 48:S69-S84.

Heath, M. C. 2000. Nonhost resistance and nonspecific plant defenses. Curr. Opinion Plant Biol. 3:3154-319.

Jafary, H., Albertazzi, G., Marcel, T. C., and Niks, R. E. 2008. High diversity of genes for nonhost resistance of barley to heterologous rust fungi. Genetics 78:2327-2339.

Jones, J. D. G., and Dangl, J. L. 2006. The plant immune system. Nature 444:323-329.

Leppik, E. E. 1961. IV. Stem rust genealogy. Mycologia 53:378-405.

Lipka, V., Dittgen, J., Bednarek, P., Bhat, R., Wiermer, M., Stein, M., Landtag, J., Brandt, W., Rosahl, S., Scheel, D., Lllorente, F., Molina, A., Parker, J., Somerville, S., and Schulze-Lefert, P. 2005. Pre- and postinvasion defenses both contribute to nonhost resistance in Arabidopsis. Science 310:1180-1183.

Mellersch, D. G., and Heath, M. C. 2003. An investigation into the involvement of defense signalling pathways in components of the nonhost resistance of Arabidopsis to rust fungi also reveals a model system for studying rust fungal compatibility. Mol. Plant-Microbe Interact. 16:398404.

Nakao, M., Nakamura, R., Kita, K., Inukai, R., and Ishikawa, A. 2011. Non-host resistance to penetration and hyphal growth of Magnaporthe oryzae in Arabidopsis. Sci. Rep. 1:171. doi:10.1038/srep00171. Published online.

Paterson, A. H., Bower, J. E., and Chapman, B. A. 2004. Ancient polyploidization predating divergence of the cereals, and its consequences for comparative genomics. Proc. Natl. Acad. Sci. U.S.A. 101:99039908

Rafiqi, M., Ellis, J. G., Ludowici, V. A., Hardham, A. R., and Dodds, P. N. 2012. Challenges and progress towards understanding the role of effectors in plant-fungal interactions. Curr. Opin. Plant Biol. 15:477-482.

Raskin, I., Skubatz, H., Tang, W., and Meeuse, B. J. D. 1990. Salicylic acid levels in thermogenic and nonthermogenic plants. Ann. Bot. 66:363-373.

Schulze-Lefert, P., and Pangstruga, R. 2011. A molecular evolutionary concept connecting nonhost resistance, pathogen host range and pathogen speciation. Trends Plant Sci. 16:117-125.

Shafiei, R., Hang, C., Kang, J.-G., and Loake, G. J. 2007. Identification of loci controlling non-host disease resistance in Arabidopsis against the leaf rust pathogen Puccinia triticina. Mol. Plant Pathol. 8:773-784.

Silverman, P., Seskar, M., Kanter, D., Scheizer, P., Metraux, J.-P., and Raskin, I. 1995. Salicylic acid in rice: Biosynthesis, conjugation and possible role. Plant Physiol. 108:633-639.

Song, R. J., Davis, J. I., and Voionmaa, M. A. 2007. A phylogenetic analysis of Poaceae tribe Poeae sensu lato based upon morphological characters and sequence data from three plastid-encoded genes: Evidence for reticulation, and a new classification for the tribe. Kew Bull. 62:425454.

Stein, M., Dittgen, J., Sanchez-Rodriguez, C., Hou, B.-H., Molina, A., Schulze-Lefert, P., Lipka, V., and Somerville, S. 2006. Arabidopsis PEN3/PDR8, an ATP binding cassette transporter, contributes to nonhost resistance to inappropriate pathogens that enter by direct penetration. Plant Cell 18:731-746.

Vogel, J. P., Garvin, D. F., Leong, O. M., and Hayden, D. M. 2006. Agrobacterium-mediated transformation and inbred line development in the model grass Brachypodium distachyon. Plant Cell Tiss. Org. Cult. 84:199-211.

Vogel, J. P., Tuna, M., Budak, H., Huo, N., Gu, Y. Q., and Steinwand, M. A. 2009. Development of SSR markers and analysis of diversity in Turkish populations of Brachypodium distachyon. BMC Plant Biol. 9:88.

Wahl, I., Anikster, Y., Manisterski, J., and Segal, A. 1984. Evolution at the center of origin. Pages 39-77 in: Origins, Specificity, Structure, and Physiology. The Cereal Rusts, Vol. 1. W. R. Bushnell and A. P. Roelfs, eds. Academic Press, Orlando, FL, U.S.A.

Zambino, P. J., and Szabo, L. J. 1993. Phylogenetic relationship of selected cereal rusts based on rRNA sequence analysis. Mycologia 85:401-414. 